\title{
Pensamento pós-abissal e pós-colonialismo em Boaventura de Sousa Santos: críticas e avanços epistemológicos
}

\author{
João Paulo de Almeida Amorim ${ }^{1}$ \\ 1 Mestre em Desenvolvimento Regional pela Universidade Federal do Amapá, Pós-graduado em Docência do Ensino Superior \\ pela Faculdade Meta, Graduado em Geografia pela Universidade Federal do Amapá. Professor efetivo de Geografia da rede \\ estadual de ensino do Estado do Amapá, Brasil. E-mail: joaopauloamorim30@gmail.com
}

RESUM 0: Este artigo visa estudar e refletir sobre o desenvolvimento do pensamento pós-abissal e sua relação epistemológica com a teoria pós-colonial. Para tanto, a metodologia utilizada considera obras de referência no pós-colonialismo latino-americano como Lander (2005), Bonnici (1998), M ignolo (2005), além de Santos (2002; 2007; 2008), que são referências para discutir a questão pós-colonial na atualidade. Verificou-se através da análise da teoria pós-colonial e o pensamento pós-abissal que, essas teorias têm um eixo comum, que é a crítica ao modo de visão de mundo adotado pelo modelo ocidental hegemônico, construído, principalmente, nos países colonizadores. Em seguida, segue o debate acerca das possíveis saídas para o gargalo epistêmico em que se encontram as ciências sociais. As práticas sociais visadas por Boaventura são o cosmopolitismo subalterno, tradução intercultural, artesania das práticas e os saberes alternativos nãocientíficos. Além disso, a reflexão passa pela crítica feita ao marxismo por Boaventura e sua discussão de como Marx enxergava o colonialismo. Por fim, discute-se de como pode-se aprofundar o debate, suas possíveis limitações e avanços epistêmicos desenvolvidos, considerações e críticas construtivas, além da reflexão sobre o debate do pensamento pós-colonial no Brasil, que apresenta, ainda, poucos autores escrevendo sobre a teoria pós-colonial.

Palavras-chave: Epistemologia; Pós-colonialismo; Pós-abissal; Ciências Sociais.

\section{Thought post-abyssal and post-colonialism in de Sousa Santos Boaventura thought: critical and advances epistemological}

ABSTRACT: This article aims to study and reflect on the development of post-abyssal thinking and its epistemological relationship with postcolonial theory. Therefore, the methodology considers reference works in the Latin American postcolonialism as Lander (2005), Bonnici (1998), M ignolo (2005) and Santos (2002; 2007; 2008), which are references to discuss the postcolonial question today. It was found through the analysis of postcolonial theory and post-abyssal thinking that these theories have a common axis, which is critical to the world view mode adopted by the Western hegemonic model, built mainly in the colonizing countries. Then follows the debate about possible solutions to the epistemic bottleneck where are the social sciences. Social practices targeted by Boaventura are the subaltern cosmopolitanism, intercultural translation, craftsmanship practices and nonscientific alternative knowledge. In addition, the reflection passes through the critique of Marxism by Boaventura and his discussion of how Marx saw coIonialism. Finally, we discuss how we can deepen the debate, their possible limitations and developed epistemic advances, considerations and constructive criticism, as well as reflection on the debate of the postcolonial thought in Brazil, which has also few authors writing on post-colonial theory.

Keywords: Epistemology; Post-Colonialism; Post-abyssal; Social Sciences. 


\section{INTRODUÇÃO}

0 objetivo deste trabalho é refletir sobre se o pensamento pós-abissal de Boaventura de Sousa Santos (2002; 2007; 2008) rompe com os anseios sociais advindos da tradição moderna de pensar e agir do homem. E discutir quais os avanços de seu discurso com o pensamento pós-colonial.

Nesse contexto, 0 artigo está estruturado, primeiramente na proximidade conceitual entre os conceitos sobre o pensamento pós-colonial e pós-abissal presente em Santos (2002; 2008). Em seguida, analisa-se o avanço dos estudos acerca da epistemologia social e a contribuição do discurso pós-colonial, através da inserção de novos conceitos de pesquisa apresentado pelos trabalhos de Boaventura. Na terceira parte, o debate sobre a superação ou não do discurso marxista, através das novas práticas sociais tomam espaço na construção deste artigo.

A escolha desses elementos está na possibilidade de verificar suas proposições, ideias e discussões acerca do que vem sendo debatido sobre esta temática. Além disso, a busca por proposições que enriqueçam os estudos pós-coloniais no Brasil e na América Latina merecem um cuidado mais acurado por parte de pesquisadores e cientistas sociais, visto o leque de conceitos que podem ser utilizados e melhorados no debate ora apresentado.

\section{PÓS-COLONIAL E PÓS-ABISSAL: APROXIM AÇÕES EPISTEM OLÓGICAS}

A teoria do pensamento pós-colonial tem sido muito debatida nas ciências humanas na atualidade. 0 entendimento sobre 0 que vem a ser o objeto de estudo deste artigo mostra sua importância no quadro das ciências sociais. Para isto, é preciso mostrar o conceito do que vem a ser pós-colonial e pós-abissal. Para alguns autores, como Mignolo (2005) e Lander (2005) a expressão "pós-colonial" significa a descrição cultural influenciada pelo processo imperial desde os primórdios da colonização até os dias de hoje. Embora não haja um consenso sobre o conteúdo do termo "Póscolonialismo" (BONNICl, 1998). Ou nas próprias palavras do próprio autor fica mais claro o que vem a ser teoria pós-colonial:

Outro conceito a ser considerado é o de literatura pós-colonial, que pode ser entendida como toda a produção literária dos povos colonizados pelas potências europeias entre o século XV e XX. Portanto, as literaturas em língua espanhola nos países latino-americanos e caribenhos; em português no Brasil, Angola, Cabo Verde e Moçambique; em inglês na Austrália, Nova Zelândia, Canadá, Índia, M alta, Gibraltar, ilhas do Pacífico e do Caribe, Nigéria, Quênia, África do Sul; em francês na Argélia, Tunísia e vários países da África, são literaturas pós-coloniais (BONNICl, 1998, p. 09).

O que se pode inferir da passagem acima é que há vários países, de vários continentes envolvidos em um mesmo tempo cronológico de estudo. No entanto, o tempo 
social de cada um obedece a especificidades histórico-sociais próprias, mas que possuem um tronco comum que seria o colonialismo.

Segundo Santos (2009), o pensamento pós-abissal se resume em criar uma nova forma de se pensar a sociedade atual em que a justiça cognitiva global seja igualitária, quer dizer, que a apropriação e a construção do discurso intelectual no mundo seja igual, quebrando o paradigma da produção e apropriação do conhecimento, a partir do ocidente hegemônico. E essa injustiça cognitiva reflete na injustiça social no mundo, atualmente.

O pensamento pós-colonial está calcado na análise da construção histórica e cultural das sociedades colonizadas a partir dos séculos XV e XVI. Essa construção se deu pelos europeus, trazendo consigo o conceito de modernidade para justificar ideologicamente sua dominação sobre os povos nativos. Lander (2005) afirma que o póscolonialismo discute sobre as diferentes formas de desenvolvimento e apropriação do conhecimento gerado no mundo, e que esse conhecimento deve ser reformulado na medida em que somente se reconhece 0 saber dos povos dominantes, que reproduzem seus saberes em escala universal. Logo, é importante criar um discurso a partir da nossa história, a história negada e silenciada dos primeiros habitantes do continente americano.

As correntes dominantes (principalmente o discurso eurocêntrico e anglo-saxão) que contêm os poderes e os saberes são um conjunto de práticas cognitivas e critérios de validação de conhecimento a partir da experiência de grupos sociais que tem sofrido com o sistema capitalista (MIGNOLO, 2005). As relações sociais são sempre culturais e políticas, representam formas de poder e distribuições desiguais de poder e o conhecimento é a manifestação desse complexo e dessa teia de relações sociais de exploração e dominação (SANTOS, 2009). Segundo Lander (2005) nos encontramos numa linha de chegada numa sociedade sem ideologias, onde se acredita num modelo civilizatório único, globalizado, universal, que torna desnecessária a política, na medida em que já não há alternativas possíveis a este modo de vida.

Esse processo marcou o início de uma história universal e de um processo irreversível de isolamento, onde todas essas relações de ordem econômica, política, cultural e espacial, possibilitaram a absorção ideológica, cultural e social de relações estrangeiras do ocidente colonizador.

Segundo Santos (2008) as linhas cartográficas, a partir do século XV e XVI inauguraram, desde seu início, uma forma de pensar e agir que justificava o uso da apropriação/violência como mecanismo legitimador da imposição cultural, intelectual, econômica e política nas colônias de Além-mar. Seus costumes, línguas, modos de viver, classificados como não-humanos, sub-humanos e selvagens. Mignolo $(2005$, p. 34) afirma que:

A emergência do circuito comercial do atlântico, no século XVI teve um profundo impacto na formação do mundo moderno/ocidental, no qual estamos vivendo e somos testemunhas. A partir deste momento, do momento de 
emergência e consolidação do circuito comercial do Atlântico, já não é possível conceber a modernidade sem a colonialidade, o lado silenciado pela imagem reflexiva que a modernidade (por ex.: os intelectuais, o discurso 0 ficial do Estado) construiu de si mesma e que o discurso pós-moderno criticou do interior da modernidade como autoimagem do poder. A pósmodernidade, autoconcedida na linha unilateral da história do mundo moderno, continua ocultando a colonialidade, e mantém a lógica universal e monotópica da esquerda e da direita da Europa (ou do Atlântico Norte) para fora. A diferença colonial (imaginada no pagão, no bárbaro, no subdesenvolvido) é um lugar passivo nos discursos pós-modernos.

Também há concordância no pensamento de Lander (1997), quando afirma que a conquista ibérica do continente americano é o momento inaugural dos dois processos que, de forma conjunta, conformam a história posterior: a modernidade e a organização colonial do mundo.

0 próprio conceito de cidadania, ainda no século XIX, recebeu nas colônias a funcionalidade jurídico-politica, baseada nas constituições em que ser cidadão passava por um crivo social em que os indivíduos que não cumpriam requisitos como ser branco, heterossexual, católico, letrado, proprietário de terras não poderia ser considerado cidadão. Logo, a maioria da população (mulheres, empregados, loucos, analfabetos, negros, hereges, escravos, índios, homossexuais, dissidentes) eram considerados reclusos no âmbito da ilegalidade, submetidos ao castigo e à terapia por parte da mesma lei que os excluiu (CASTRO-GÓM EZ, 2005).

Surge, dessa forma, o fenômeno descrito por Castro-Gómez (2005, p. 81) como a "invenção do outro". 0 autor assim o descreve:

Ao falar de "invenção" não nos referimos somente ao modo como um certo grupo de pessoas se representa mentalmente a outras, mas nos referimos aos dispositivos de saber/poder que servem de ponto de partida para a construção dessas representações. Mais que como 0 "ocultamento" de uma identidade cultural preexistente, o problema do "outro" deve ser teoricamente abordado da perspectiva do processo de produção material e simbólica no qual se viram envolvidas as sociedades ocidentais a partir do século XVI (GOM EZ, 2005, p. 81).

Assim, o conceito de cidadão da modernidade foi forjado intrinsicamente com a invenção do outro. 0 "outro" é o ser humano excluído de seus direitos civis em sua materialidade concreta, portanto, desprovido de se encontrar em condições iguais de busca de qualidade de vida e apropriação de conhecimento.

Depois da euforia cientista do século XIX e da consequente aversão à reflexão filosófica, bem simbolizada pelo positivismo, "chegam a finais do século XX possuídos pelo desejo quase desesperado de complementarmos o conhecimento das coisas com o conhecimento do conhecimento das coisas" (SANTOS, 1986, p. 12). 


\section{OS AVANÇOS EPISTÊMICOS}

As ciências sociais contribuíram efetivamente com a construção do saber eurocêntrico, fundador da modernidade que criou o modo de vida e saber como pressuposto da evolução social ditada pela marcha do conhecimento cientifico sistematizado. 0 que acabou por forjar um metarrelato universal dos saberes dos colonizadores. "Este metarrelato da modernidade é um dispositivo de conhecimento colonial e imperial em que se articula essa totalidade de povos, tempo e espaço como parte da organização colonial/imperial do mundo" (LANDER, 2005, p. 13).

A perspectiva pós-colonial está baseada na mesma visão pós-abissal de Santos (2008, p. 30), quando o autor afirma que "a negação de uma parte da humanidade é sacrificial, na medida em que constitui a condição para a outra parte da humanidade se afirmar enquanto universal". 0 sujeito pós-colonial corrobora várias identidades, ao mesmo tempo em que, as instrumentaliza, de acordo com as perspectivas situacionais, além de utilizar as segmentações específicas de cada local, sem perder de vista seu contexto mais amplo. A pós-colonialidade não é então um momento à parte a história ocidental europeia, mas sim "tangencial" a ela (Op. Cit.).

0 pensamento de Santos (2008) está na ideia de que as linhas cartográficas estabelecidas no início dos séculos XV e XVI estão vivas, mas de forma metafórica e são traçadas por lógicas de segregação de diversos tipos: fascismo territorial, fascismo social, legislação antiterrorista, leis contra imigração. Além disso, o uso da ciência moderna a favor da sociedade global, em detrimento do uso restrito da produção do saber e 0 descaso com os outros saberes, que não o cientifico contribuem para a manutenção da ordem epistemológica vigente.

Esta visão hegemônica da ciência moderna veio sendo refutada, principalmente, nas duas últimas décadas do século XX. A teoria da falseabilidade de Popper (1975), onde os paradigmas do conhecimento científico são passiveis de falsear, a teoria das estruturas dissipativas de Prigogine ${ }^{1}$ põe em xeque a visão do paradigma dominante. 0 que ratifica a importância de uma construção de saberes que foram postos de lado e, muitas vezes, desconsiderados como ciência.

Santos (1986) destaca a importância da ruptura do paradigma dominante quando afirma que:

Este movimento científico e as demais inovações teóricas que atrás define como outras tantas condições teóricas da crise do paradigma dominante têm vindo a propiciar uma profunda reflexão epistemológica sobre o conhecimento científico, uma reflexão de tal modo rica e diversificada que, meIhor do que qualquer outra circunstância, caracteriza exemplarmente a situação intelectual do tempo presente. (SANTOS, 1986, p. 12).

${ }^{1}$ Segundo Prigogine (1997) a teoria das estruturas dissipativas estuda sistemas abertos, onde o ponto de entropia busca o equilíbrio do sistema, estando apta a evolução. Dessa conclusão a Teoria da evolução de Darwin e as leis da Termodinâmica encontram um ponto em comum, dando uma nova visão para a ciência. 
Este avanço epistêmico tem de ser considerado em seu contexto social. Visto que, as relações sociais em que são produzidas, são relações em que o modelo segregação/emancipação estão ligados, enquanto que, no pensamento pós-colonial deve ser inserido noutro contexto, o da apropriação/violência, no qual as condições de pensamento levam em consideração o legado colonial calcado na exploração e dominação dos povos da América latina e América Central.

Para Santos (2009), o uso contra-hegemônico da ciência moderna não pode se limitar ao saber cientifico. É preciso absorver os saberes alternativos não-científicos, visto que, o saber cientifico é elitizado e manipulado por um pequeno grupo de pesquisadores. Logo, a universalidade do saber se desfaz pela falta de apropriação do conhecimento por todos os grupos sociais, assim como a negação da existência de outros saberes. 0 conhecimento científico moderno é um conhecimento desencantado e triste que transforma a natureza num autômato, ou, como diz Prigogine (1997), num interlocutor terrivelmente estúpido (SANTOS, 1986).

Essa possível emergência subalterna de se repensar a apropriação do saber consegue, num primeiro instante, diminuir ou suprimir as diferenças entre os saberes, além de estreitar a linha abissal entre os povos.

No entanto, como saber se isso é suficiente para quebrar o paradigma dominante é mais complexo do que parece, pois a coexistência das práticas cognitivas cientifica e não-cientifica pode ser possível no modo hegemônico sem, no entanto, destruí-lo? Para isso, Boa ventura engendra o uso dos mecanismos de pesquisa como a tradução inter-cultural, o cosmopolitismo subalterno e a ecologia de saberes. Tavares (2011, p. 50) afirma que a verdade é que "o conhecimento moderno se tornou abstrato, desideologizado e neutro, ao afirmar-se como descontextualizado, eliminando de si todas as relações sociais de dominação que lhe serviram de suporte". Logo, há uma convergência de ideias, onde é preciso ir mais longe $n$ compreensão de um novo paradigma científico.

A tradução inter-cultural coloca as experiências dos saberes alternativos aos saberes ocidentais como complemento e fundamento de novos conceitos sobre sociedade, cultura, justiça, cidadania, entre outros, a partir da interpretação aproximada destes conceitos pelo processo de tradução (SANTOS, 2009).

0 cosmopolitismo subalterno surge como elemento alternativo à modernidade ocidental. M anifesta-se através das iniciativas e movimentos que constituem a globalização contra-hegemônica. Boaventura utiliza a expressão "globalização contrahegemônica" como processo contra a dominação hegemônica dos saberes e modo de vida (SANTOS, 2008). Procura se alimentar da infinidade de saberes existentes no mundo, e suas infinitas epistemes.

Para Santos (2009) a ecologia de saberes se baseia na ideia de que o conhecimento é interconhecimento, ou seja, a relação estreita entre os saberes. E que, existe uma intolerância com as diversas formas de saber e pensar, além da intolerância a copresença. Seus preceitos visam, também a tentar equacionar as temporalidades di- 
vergentes do tempo linear ocidental.

Na perspectiva das epistemologias abissais do Norte global, o policiamento das fronteiras do conhecimento relevante é de longe mais decisivo do que as discussões sobre diferenças internas. Como consequência, um epistemicídio maciço tem vindo a decorrer nos últimos cinco séculos, e uma riqueza imensa de experiências cognitivas tem vindo a ser desperdiçada. Para recuperar algumas destas experiências, a ecologia de saberes recorre ao seu atributo pós-abissal mais característico, a tradução intercultural. Embebidas em diferentes culturas ocidentais e não-ocidentais, estas experiências não só usam linguagens diferentes, mas também distintas categorias, diferentes universos simbólicos e aspirações a uma vida melhor (SANTOS, 2009, p. 61).

A ecologia de saberes, enquanto pratica cognitiva, se baseia na busca por experiências diversas, não somente a partir da experiência eurocêntrica, que tem aniquilado grande parte do saber que é produzido no mundo, como não-ciência, e na tentativa de aglutinar experiências filosóficas distintas que se utilizam de expressões diferenciadas.

\section{MARXISM O: CRÍTICA OU AVANÇO EPISTÊMICO?}

Para Santos, o pós-colonialismo surge como prática científica alternativa, enquanto que, o pensamento pós-abissal como pratica cognitiva libertadora. Porém, como conceber o pensamento pós-abissal como pratica libertadora se os movimentos sociais são práticas assentadas na busca por direitos que não questionam o modo de vivencia atual? Para Silva (2011) as lutas reivindicativas desses sujeitos são travadas em busca de conquistas modernas como escola, propriedade da terra, leis de proteção social, enfim, direitos básicos do Estado burguês e não contra excessos da regulação da modernidade ${ }^{2}$.

Silva (2011) ainda afirma que o pensamento de Boaventura é incipiente na interpretação do marxismo:

Ao mesmo tempo, sabemos que a homogeneização das identidades, o não reconhecimento da diversidade cultural e religiosa, a padronização de comportamentos e valores é uma realidade, mas não se contrapõem frontalmente com a tradição do pensamento crítico moderno, principalmente com a teoria marxista, em suas mais variadas correntes, como insiste o professor português (SILVA, 2011, p. 11).

No entanto, a crítica de Boaventura ao Marxismo não chega a ser suficiente e tão concisa como afirma Silva. Em Santos (2008), o autor concebe o Marxismo e o Libera-

${ }^{2}$ Aí estão inclusos os ditos Novos Movimentos Sociais NM S's. Dentre eles destaque para os movimentos indígenas, O Fórum Social M undial e o Movimento Feminista. 
lismo político como parte de processos tradicionais de pensamento moderno e, que, a primeira corrente, ainda hoje, sustenta a argumentação teórica das teorias póscoloniais. Ou seja, não descarta a teoria marxista, tampouco se exime de sua importância epistemológica atualmente. Segundo o autor:

A tensão entre regulação e emancipação social é constitutiva das duas grandes tradições teóricas da modernidade ocidental - o liberalismo político e o marxismo. As diferenças entre eles são significativas, pois enquanto 0 liberalismo político confina as possibilidades de emancipação ao horizonte capitalista, o marxismo concebe a emancipação social num horizonte póscapitalista. No entanto, ambos concebem o colonialismo no quadro historicista de um código temporal que coloca os povos coloniais na "sala de espera" da história, que, a seu tempo, Ihes trará os benefícios da civilização. Isto não impede que se reconheça que, dado o caráter constitutivamente colonialista do capitalismo moderno, o horizonte pós-capitalista desenhado pelo marxismo seja também um horizonte pós-colonial. Não surpreende, por isso, que, de todas as tradições teóricas europeias e eurocêntricas, 0 marxismo seja a que mais tenha contribuído para os estudos pós-coloniais, retirando daí parte da sua renovada vitalidade (SANTOS, 2004, p. 15).

É nesse contexto que se enquadra a crítica de Santos ao marxismo, quando se trata de colocar os povos colonizados na "sala de espera" da construção histórica de emancipação social. Quando o que se espera é justamente o contrário, ou seja, a construção de uma nova epistemologia baseada na intervenção dos povos colonizados na sua própria história.

Além disso, Santos (1999) analisa as fases da discussão do pensamento marxista por diversos autores ao longo do século XX. Nesta análise identifica que, durante as décadas de 1950 a 1970, o marxismo ganhou força nos movimentos anti-coloniais, no surgimento de novos países na Europa, na Revolução Cubana e sustentou governos calcados no discurso comunista. Fato notado, também pela sua reconstrução e revisão teórica por autores como A. Giddens (1981), J. Habermas (1978) e S. Aaronowitz (1981). Ao mesmo tempo em que era revisto, o marxismo propiciou novos debates na Sociologia, propiciando seu crescimento epistemológico. No entanto, na década de 80 sofre críticas com o fim do socialismo em diversos países.

Quanto à construção epistemológica de Santos, Silva (2011) se equivoca em outra passagem de seu texto quando afirma:

Em nossa avaliação, algumas das principais teses apresentadas por Boaventura de Sousa Santos não se sustentam ou, entram em contradições irreconciliáveis. Neste sentido, muitas das elaborações teórico-reflexivas do pensador lusitano, assumem um sentido contrário as suas próprias pretensões. 0 que serviria para orientar a caminhada da construção de um pensamento crítico e uma intervenção política emancipatória, acaba por dificultar uma leitura mais responsável e coerente sobre a dinâmica das lutas contemporâneas e os desafios das classes subalternas diante da ofensiva 
global do capital. Ao mesmo tempo em que refuta qualquer perspectiva epistêmica que pretenda oferecer uma visão de totalidade sobre a realidade, propõe como forma de contraposição ao modelo de globalização hegemônico uma globalização contra-hegemônica, batizada por ele de cosmopolitismo subalterno, que tem como principal desafio lutar pela justiça global. Isso não seria uma teoria geral? Uma metanarrativa, por ele tão demonizada? (SILVA, 2011, p. 08-09, grifo do autor).

A uma leitura mais atenta do autor é incipiente dizer que Boaventura deseja construir uma metanarrativa. Não é esse o foco do autor quando se fala em cosmopolitismo subalterno. 0 intuito dessa ideia é, justamente, o contrário, buscar na ecologia de saberes a saída para o gargalo epistêmico que se encontra, hoje, a ciência. Ou seja, a busca de mecanismos alternativos de saberes, onde não predomine uma única ideia, um único motor de pensamento, mas várias saídas, várias ideias, várias alternativas para o modo de produção capitalista. Nisto reside o pensamento de Santos.

Para Santos $(2009$, p. 30$)$ "o lugar de enunciação da ecologia de saberes são todos os lugares onde o saber é convocado a converter-se em experiência transformadora". Cabe aqui ressaltar que o projeto contra-hegemônico está baseado, principalmente, na pretensão de buscar os inter-movimentos sociais, ou seja, cada vez mais se estabelecer os diálogos entre os diversos movimentos que se encontram vigentes, atualmente. 0 objetivo deste é o de evitar o que 0 autor chama de fascismo epistemológi$\mathrm{co}^{3}$. É quando se constitui uma relação violenta de destruição ou supressão de outros saberes. Fato esse, que eliminou grande parte dos saberes alternativos existentes em várias partes do mundo que foram suprimidos no período colonial, causando seu epistemicídio ${ }^{4}$.

No entanto, a ecologia de saberes possui suas limitações. Por exemplo, de que forma sistematizar um conjunto de saberes, que é infinito, sem deixar alguns de fora? Como estabelecer comparações entre os saberes, visto que, suas tradições teóricas, culturais e políticas são engendradas de formas muito distintas? Para o autor, o mecanismo de Tradução e a Artesania das práticas seria necessário para se começar a discussão epistemológica entre os saberes.

0 trabalho de tradução esta pautado na tradução intercultural dos saberes pertencentes a mesma cultura ou a culturas diferenciadas. 0 procedimento de tradução de expressões que só existem em algumas etnias, povos e grupos sociais dificulta o procedimento. Logo, a universalização e a difusão do saber se torna mais complexo, pois é preciso fazer aproximações sucessivas entre as línguas para se chegar ao entendimento. Porém, as aproximações sucessivas podem descaracterizar o pensamento inicial, remodelando, por vezes, de forma errônea o pensamento inicial. Mas, ao

\footnotetext{
${ }^{3}$ Para Boaventura, esta prática seria a não-aceitação de outras epistemes que divergem ou apresentam uma nova visão de mundo, que não a eurocêntrica (SANTOS, 2009).

${ }^{4} \mathrm{O}$ autor refere-se à epistemicídio como 0 silenciamento das epistemologias não científicas através de sua supressão e/ ou eliminação (SANTOS, 2002).
} 
mesmo tempo, os saberes introduzidos podem desenvolver sobre as muitas ideias alternativas que ela pode exprimir e que a filosofia ocidental não pode.

A Artesania das práticas está pautada na preocupação em estabelecer contextos específicos, onde os saberes se integrarão em um dado exercício da ecologia de saberes. Destes dois procedimentos pode-se resultar em discussões que tem um eixo em comum:

A preocupação da preservação da biodiversidade pode levar a uma ecologia entre 0 saber científico e o saber camponês ou indígena. A preocupação da luta contra a discriminação pode conduzir a uma ecologia entre saberes produzidos por diferentes movimentos sociais: feministas, antirracistas, de orientação sexual, de direitos humanos, indígenas, afrodescendentes, etc., etc. A preocupação com a dimensão espiritual da transformação social pode levar a ecologias entre saberes religiosos e seculares, entre ciência e misticismo, entre teologias da libertação (feministas, pós-coloniais) e filosofias ocidentais, orientais, indígenas, africanas, etc. A preocupação com a dimensão ética e artística da transformação social pode incluir todos esses saberes e ainda as humanidades, no seu conjunto, a literatura e as artes (SANTOS, 2008, p. 30).

Pensando nesta ideia, Santos (2008) trabalha com o projeto contra-hegemônico a partir do desenvolvimento do que o autor chama de Epistemologias do sul. Se não houvesse epistemologias do norte não seriam necessárias epistemologias do sul. São diferenças verticais que surgem como uma proposta epistemológica insurgente, contra um projeto de dominação capitalista mundial, que são o paradigma hegemônico.

Segundo Nunes (2008, p. 48) "a epistemologia do Sul, enquanto projecto, significa, ao mesmo tempo, uma descontinuidade radical com o projeto moderno da epistemologia e uma reconstrução da reflexão sobre os saberes". Para tanto, o pragmatismo epistemológico é uma das bases teorizadas por Boaventura para ratificar seu pensamento.

O Sul aparece como o projeto de insurgência contra o paradigma hegemônico. Além de uma mera posição geográfica, "está relacionado a uma construção geopolítica, que se inicia com a expansão colonial da Europa e que se apresenta hoje sob a roupagem da globalização neoliberal" (TAVARES, 2011, p. 15). No entanto, as relações produzidas no colonialismo enquanto relação política não acarretou seu fim enquanto relação social.

É possível fazer uma referência tanto ao pragmatismo quanto à epistemologia para utilizá-las de forma associada. A partir desse contexto pode-se nortear o uso das experiências dos oprimidos com modo alternativo além de, ao mesmo tempo, estabelecer ligações com a crítica da epistemologia enquanto projeto filosófico e romper com os pressupostos e condições dessa crítica. Torna-se possível, assim, uma dupla opera- 
ção de "resgate" da epistemologia".

Os pressupostos históricos, reproduzidos ao longo do tempo, como a imposição de uma visão monocultural e linear de tempo, resulta de condições escondidas e suprimidas, que, por destaque na cultura ocidental acabaram se afirmando como verdades inquestionáveis e únicas. Ou seja, a sociedade moderna ocidental estava assentada em uma falsa moralidade. Filósofos questionaram essa moralidade. Dentre eles, se destaca Nietzsche (2013). o filósofo alemão criticava a sociedade moderna através de sua crítica à moralidade:

0 mais moral é aquele que mais sacrifica aos costumes (...). Em compensação, esses moralistas que, semelhantes aos sucessores de Sócrates, recomendam ao indivíduo o domínio de si e a sobriedade, como suas vantagens mais especificas, como a chave mais pessoal de sua felicidade, esses moralistas constituem a exceção - e se vemos as coisas de outro modo é porque simplesmente fomos criados sob a influência deles: todos seguem uma vida nova que lhes vale a mais severa reprovação dos representantes da moralidade dos costumes - eles se excluem da comunidade, uma vez que são imorais, e são, na acepção mais profunda do termo, maus (NIETZSCHE, 2013, p. 24).

A cultura dominante, eurocêntrica, etnocêntrica, que se afirmou historicamente como hegemônica, os conhecimentos que ela produziu, os valores que foram impostos, o modelo de racionalidade que configurou conhecimentos, valores morais, estéticos e religiosos, tomou a sua produção como verdade universal e absoluta.

É possível, desse modo, analisar a extensão dos novos horizontes de pensamento abertos pela busca outras lógicas outras racionalidades, particularmente as oprimidas e historicamente silenciadas, no contexto dos pensamentos pós-coloniais e pósabissais.

Para isso, é preciso repensar nossas ações, a partir de uma nova lógica de produção e apropriação do conhecimento onde sejam respeitadas as diferentes formas de pensar a agir não-ocidentais. Nesse sentido, concorda-se com Santos (2001, p. 23), quando afirma que é preciso "pensar e agir, como pensar o pensar". Ou seja, refletir sobre as condições e desafios que são impostos perante a sociedade e a condição epistêmica em que se encontra atualmente.

\section{PARA ENRIQUECER O DEBATE}

Diante da discussão apresentada fica claro que, se faz cada vez mais necessário o desenvolvimento das teorias pós-coloniais e o pensamento pós-abissal, pois seu discurso interessa diretamente a América Latina e as ex-colônias que foram vítimas das

\footnotetext{
${ }^{5}$ Nunes (2008) usa o termo para identificar a concepção de epistemologia numa acepção de busca de seus pressupostos, no sentido de resgatar as epistemes alternativas que Boaventura de Sousa santos analisa em seu artigo Sociologia das Ausências e Sociologias das Emergências.
}

PRACS: Revista Eletrônica de Humanidades do Curso de Ciências Sociais da UNIFAP 
distorções, explorações e dominação política, ideológica, econômica e cultural durante séculos dos países "ocidentais".

Portanto, a lógica de apropriação do conhecimento tem de ser questionada, revista e refutada, no que tange às epistemes que foram suprimidas e, ainda, não são consideradas como pertencentes ao domínio cientifico. Os princípios norteadores da discussão foram colocados em pauta. 0 inicio de uma proposição inovadora de compreensão teórica e epistemológica se faz latente. Logo, devemos nos propor a fomentar e dar ânimo a essa visão de mundo que enxerga uma totalidade mais completa a que vinha sendo dita como a universal.

O saber e o poder andaram juntos nos últimos séculos. Serviram de sustentação e justificativa para a dominação dos povos colonizados. Então a reinvenção do saber e a reinvenção do poder são práticas que precisam ser postas em xeque. 0 trabalho de discussão cientifica acerca da temática ainda está começando, apesar de ser iniciado na década de 1970 com os trabalhos de E. Said sobre o Orientalismo tem ganhado força nos últimos anos com as obras de Fernando Coronil, Walter Mignolo, Edgardo Lander, Ana Ester Ceceña, Arturo Escobar, Boaventura de Sousa Santos, Partha Chatterjee, Homi Bhabha, entre outros, não menos importantes.

No Brasil, a discussão pós-colonial e pós-abissal ainda é incipiente. No entanto, Carlos Walter Porto Gonçalves lidera os primeiros debates sobre o tema. Os estudos sobre a construção social e antropológica das populações antes do "descobrimento" português, além das consequências da lógica de apropriação/violência ocorrida nos primeiros séculos de colonização no Brasil, podem engendrar o entendimento as origens da desigualdade social e espacial desenvolvida no seio da sociedade brasileira.

Além disso, é preciso questionar e pesquisar os parâmetros pós-coloniais na formação e adoção do idioma português e de sua apropriação na formação da literatura após a independência política e, especialmente, no modernismo e nos anos que 0 seguem. Logo, ainda temos muito a pesquisar e desenvolver sobre as consequências do colonialismo, nos diversos campos das ciências sociais, na ex-colônia portuguesa.

A teoria pós-colonial e o pensamento pós-abissal de Boaventura de Sousa Santos estão mais próximos do que se previa. No entanto, se apresentam sob óticas distintas de construção do saber, além disso, o pensamento pós-abissal apresenta possíveis saídas para a supressão sistêmica do saber eurocêntrico, enquanto que o póscolonialismo identifica as raízes dessa submissão do pensamento e norteia as discussões acerca daquilo que foi e continua sendo usado como discurso hegemônico na prática de construção social, cultural, histórica e cientifica sobre o papel das sociedades colonizadas durante séculos de dominação e exploração, que acarretou em supressões, extinções e desuso de práticas socioculturais que nos pertencem como identidade cultural e social. 


\section{REFERÊNCIAS}

BONNICl, T. Introdução ao estudo das literaturas pós-coloniais. Mimesis, Bauru, v. 19, n. 1, p. 07-23, 1998.

CASTRO-GÓM EZ, Santiago. Ciências sociais, violência epistêmica e o problema da "invenção do outro". In: A colonialidade do saber: eurocentrismo e ciências sociais. Perspectivas latino-americanas. Buenos Aires: CLACSO, 2005. p. 80-87.

LANDER, Edgardo. Ciências Sociais: saberes coloniais e eurocêntricos. In: (org.). A colonialidade do saber: eurocentrismo e ciências sociais. Perspectivas latino-americanas. Buenos Aires: CLACSO, 2005. p. 8-23.

. Modernidad, Colonialidad e Postmodernidad. Revista Venezolana de Economia y Ciencias Sociales, $n^{\circ} 4$, Caracas, out-dez., 1997.

M IGNOLO, Walter. A colonialidade de cabo a rabo: o hemisfério ocidental no horizonte conceitual da modernidade. In: LANDER, Edgardo (org.). A colonialidade do saber: eurocentrismo e ciências sociais. Perspectivas latino-americanas. Buenos Aires: CLACSO, 2005. p. 33-49.

NIETZSCHE, Friedrich Wilhelm. BRAGA, A. C. (trad.). Aurora. São Paulo: Escala, 2013. NUNES, J. Arriscado. 0 resgate da epistemologia. Revista Crítica de Ciências Sociais, v. 80, p. 45-70, mar. 2008.

POPPER, Karl. A lógica da pesquisa científica. São Paulo: Cultrix/Edusp, 1975.

PRIGOGINE, Ilya. The End Of Certainty: Time, Chaos, and The New Laws of Nature. New York: Free Press, 1997.

SANTOS, Boaventura de Sousa. Um Discurso Sobre as Ciências. Universidade de Coimbra, Portugal, p. 1-22. 1986.

. Pela Mão de Alice: 0 social e o político na pós-modernidade. Porto: Afrontamento. $7^{\circ}$ ed. 1999.

. Para uma Concepção Multicultural dos Direitos Humanos. Contexto Internacional, v. 23, ano 1, p. 7-34. 2001.

. Seis razões para pensar. Lua Nova, v. 54, p. 13-24. 2001.

- Para uma sociologia das ausências e uma sociologia das emergências. Revista Crítica de Ciências Sociais, v. 63, p. 237-280. 2002.

. A filosofia à venda, a douta ignorância e a aposta de Pascal. Revista Crítica de Ciências Sociais, v. 80, p. 11-43. 2008.

. Para além do pensamento abissal: das linhas globais a uma ecologia dos saberes. In SANTOS, B. S. \& M ENESES, Maria Paula (Orgs.). Epistemologias do Sul. Coimbra: Livraria Almedina, 2009, p. 30-65.

. Do pós-moderno ao pós-colonial e para além de um e de outro. Centro de Estudos Sociais da Faculdade de Economia da Universidade de Coimbra. s/d.

SANTOS, Boaventura de Sousa; Gomes, Conceição. Geografia e democracia para uma nova justiça. Julgar, v. 2, p. 109-128. 2007.

SILVA, P. C. Dutra. De pós a pós, a lugar nenhum: uma crítica ao pensamento de Boa- 
ventura de Sousa Santos. V Encontro Brasileiro De Educação e Marxismo. UFSC, Florianópolis. Abril, 2011.

TAVARES, Manuel. Despensar as pedagogias coloniais e os seus pressupostos epistemológicos. VIII Colóquio de Pesquisa Sobre Instituições Escolares - Pedagogias Alternativas. ULHT, Lisboa, 2011.

Artigo recebido em 05 de maio de 2015.

Aprovado em 17 de novembro de 2016. 